\title{
Molecular characterization of highly pathogenic H5N I avian influenza viruses isolated in Sweden in 2006
}

\author{
István Kiss*1,2, Péter Gyarmati ${ }^{1}$, Siamak Zohari ${ }^{1}$, Karin Wilbe Ramsay ${ }^{1}$, \\ Giorgi Metreveli ${ }^{1}$, Elisabeth Weiss ${ }^{3}$, Maria Brytting ${ }^{4}$, Marielle Stivers ${ }^{4}$, \\ Sofia Lindström ${ }^{4}$, Ake Lundkvist ${ }^{4}$, Kirill Nemirov ${ }^{4}$, Peter Thorén ${ }^{5}$, \\ Mikael Berg${ }^{1}$, György Czifra ${ }^{1}$ and Sándor Belák ${ }^{1}$
}

Address: ${ }^{1}$ Joint Research and Development Division in Virology of the National Veterinary Institute (SVA) and Swedish University of Agricultural Sciences (SLU), and Department of Biomedical Sciences and Public Health, Section of Parasitology and Virology, SLU, Ulls väg 2B, SE-751 89 Uppsala, Sweden, ${ }^{2}$ Department of Microbiology, Central Agricultural Office, Veterinary Diagnostic Directorate, Bornemissza u. 3-7, H-4031 Debrecen, Hungary, ${ }^{3}$ University of Applied Sciences of Weihenstephan, Alte Akademie 1, D-85350 Freising-Weihenstephan, Germany, ${ }^{4}$ Swedish Institute for Infectious Disease Control, SE-171 82 Stockholm, Sweden and ${ }^{5}$ Molecular Diagnostic Section, Unit for Virology, Immunology, and Parasitology, SVA, Ulls väg 2B, SE-751 89 Uppsala, Sweden

Email: István Kiss* - istvan.kiss@sva.se; Péter Gyarmati - peter.gyarmati@sva.se; Siamak Zohari - siamak.zohari@sva.se;

Karin Wilbe Ramsay - karin.wilbe-ramsay@bvf.slu.se; Giorgi Metreveli - giorgi.metreveli@sva.se; Elisabeth Weiss - lisi.weiss@vr-web.de; Maria Brytting - mia.brytting@smi.se; Marielle Stivers - Marielle.Stivers@smi.se; Sofia Lindström - sofia.lindstrom@imbim.uu.se; Ake Lundkvist - ake.lundkvist@smi.se; Kirill Nemirov - kirill.nemirov@smi.ki.se; Peter Thorén - peter.thoren@sva.se; Mikael Berg - mikael.berg@bvf.slu.se; György Czifra - gczifra@gmail.com; Sándor Belák - sandor.belak@bvf.slu.se

* Corresponding author

Published: 6 October 2008

Virology Journal 2008, 5:113 doi:10.1186/1743-422X-5-113
Received: 22 August 2008

Accepted: 6 October 2008

This article is available from: http://www.virologyj.com/content/5/I/II3

(c) 2008 Kiss et al; licensee BioMed Central Ltd.

This is an Open Access article distributed under the terms of the Creative Commons Attribution License (http://creativecommons.org/licenses/by/2.0), which permits unrestricted use, distribution, and reproduction in any medium, provided the original work is properly cited.

\begin{abstract}
Background: The analysis of the nonstructural (NS) gene of the highly pathogenic (HP) H5NI avian influenza viruses (AIV) isolated in Sweden early 2006 indicated the co-circulation of two sublineages of these viruses at that time. In order to complete the information on their genetic features and relation to other HP H5NI AIVs the seven additional genes of twelve Swedish isolates were amplified in full length, sequenced, and characterized.
\end{abstract}

Results: The presence of two sub-lineages of HP H5NI AIVs in Sweden in 2006 was further confirmed by the phylogenetic analysis of approximately the $95 \%$ of the genome of twelve isolates that were selected on the base of differences in geographic location, timing and animal species of origin. Ten of the analyzed viruses belonged to sub-clade 2.2.2. and grouped together with German and Danish isolates, while two 2.2.I. sub-clade viruses formed a cluster with isolates of Egyptian, Italian, Slovenian, and Nigerian origin. The revealed amino acid differences between the two subgroups of Swedish viruses affected the predicted antigenicity of the surface glycoproteins, haemagglutinin and neuraminidase, rather than the nucleoprotein, polymerase basic protein 2 , and polymerase acidic protein, the main targets of the cellular immune responses. The distinctive characteristics between members of the two subgroups were identified and described.

Conclusion: The comprehensive genetic characterization of HP H5NI AIVs isolated in Sweden during the spring of 2006 is reported. Our data support previous findings on the coincidental spread of multiple sub-lineage H5NI HPAIVs via migrating aquatic birds to large distance from their origin. The detection of 2.2.I. sub-clade viruses in Sweden adds further data regarding their spread 
in the North of Europe in 2006. The close genetic relationship of Swedish isolates sub-clade 2.2.2. to the contemporary German and Danish isolates supports the proposition of the introduction and spread of a single variant of 2.2.2. sub-clade $\mathrm{H} 5 \mathrm{NI}$ avian influenza viruses in the Baltic region. The presented findings underline the importance of whole genome analysis.

\section{Background}

The first reports of outbreaks caused by highly pathogenic avian influenza viruses (HPAIV) of H5N1 subtype in 1996 originated from southern China [1]. Systematic influenza surveillances showed that distinct genetic sub-lineages of H5N1 HPAIVs, reflecting on their geographic origin, have been established since then among domestic poultry and have been transmitted to long distances by migratory waterfowl [2,3]. Europe experienced a peak of outbreaks of H5N1 HPAI in domestic poultry and wild birds in March 2006 - that was supposedly the consequence of an unusual westward movement of waterfowl from the Black Sea area [4-6]. The recent avian influenza virus strains of European-Middle Eastern-African (EMA) origin were assigned to three clades (EMA-1-3) based on the phylogeny of the complete genomes of the isolates [7], which are referred as sub-clades 2.2.1.-2.2.3. according to the more recent nomenclature [8]. Further, clade 2.2. was classified into three sub-clades: Clade 2.2.1. appeared in Egypt, southern Germany, Italy, Mongolia, and some regions in sub-Sahara Africa. Clade 2.2.2. viruses were detected in northern Germany, Denmark, Sweden, Scotland, and Nigeria, while clade 2.2.3. viruses were demonstrated in India, Afghanistan, Italy, and Iran [9]. Simultaneous transmission of different strains was reported in several European countries such as Sweden [10], Germany [9], France and Italy [11]. Characterization of the Swedish H5N1 HPAIV isolates based on the nonstructural (NS) gene nucleotide sequences demonstrated that all belonged to clade 2.2. The majority of them clustered together with clade 2.2.2., viruses belonging to clade 2.2.1. were also introduced into Sweden [10].

The aim of this study was to further investigate the Swedish H5N1 HPAI viruses by sequencing twelve selected isolates representing four east-coast provinces of the area affected by the epidemic during March-April 2006. The sequence information was used to study the evolution and epidemiology of the outbreak of H5N1 in Europe during 2006. Further, a H5N1 strain isolated from a mink was investigated to reveal any possible adaptation towards mammals.

\section{Results and discussion Phylogenetic analysis}

According to the Influenza A Virus Genotype Tool [12] the studied genes of the investigated Swedish isolates belonged to the following lineages: PB2 (K), PB1 (G), PA (D), HA (5J), NP (F), NA (1J), MP (F), NS (1E).

All twelve Swedish H5N1 isolates in this study belonged to the 2.2. clade and the phylogenetic trees of all eight genes had similar topologies. Representative trees of the HA and PB2 genes are shown (Figures 1 and 2). These data along with those generated from the other genes confirmed the close genetic relationship of H5N1 HPAIVs isolated in the northern region of Germany, Denmark and Sweden in early 2006. Two isolates out of the Swedish ones (A/tufted duck/Sweden/599/06 and A/herring gull/ Sweden/1116/06) grouped together with sub-clade 2.2.1. viruses while the other ten belonged to sub-clade 2.2.2. No viruses of sub-clade 2.2.3. were identified among the studied ones.

HA amino acid residue 403 was observed to characterize 2.2.1. (isolates mainly from Southern parts of Germany) and 2.2.2. (German isolates from the North) sub-clade German H5N1 viruses because the former group contained mainly $\mathrm{D}$ while the latter $\mathrm{N}$ at this position. All sub-clade 2.2.2. Swedish $\mathrm{H} 5 \mathrm{~N} 1$ viruses possessed $\mathrm{N}$ at HA 403 position together with A/tufted duck/Sweden/599/06 sub-clade 2.2.1. isolate, and only 2.2.1. isolate $\mathrm{A} /$ herring gull/Sweden/1116/06 had D at this site.

As far as the NA gene concerned residues $34 \mathrm{I} / \mathrm{V}, 44 \mathrm{C} / \mathrm{R}$, $305 \mathrm{~S} / \mathrm{N}$ appeared to be discriminative of sub-clade 2.2.1./ 2.2.2. isolates, respectively, consistently in case of Swedish viruses and predominantly in the analyzed additional 100 sequences. Also, at NA amino acid position 305 sub-clade 2.2.1. Swedish isolates uniquely had an $S$ while all other viruses that were analyzed (sub-clade 2.2.2. and 2.2.3. viruses) possessed $\mathrm{N}$ at this position due to a AAT $\rightarrow$ AGT transition. Sub-clade 2.2.2. Swedish viruses, and A/great crested grebe/Denmark/7498/06, A/grey lag goose/Denmark/6692/06, A/buzzard/Denmark/6370/06, A/tufted duck/Denmark/6540/06, and A/swan/Germany/R65/06 isolates possessed $\mathrm{D}$ at NA position 316 while all other analyzed viruses had $\mathrm{G}$ at this site.

The separation of the Swedish H5N1 HPAIVs into two subgroups was already demonstrated on the basis of NS gene sequences [10] and this finding was consistent for all eight genes of the isolates (herein summarized in Additional file 1). No reassortant variant was found among the sequenced twelve Swedish isolates. 


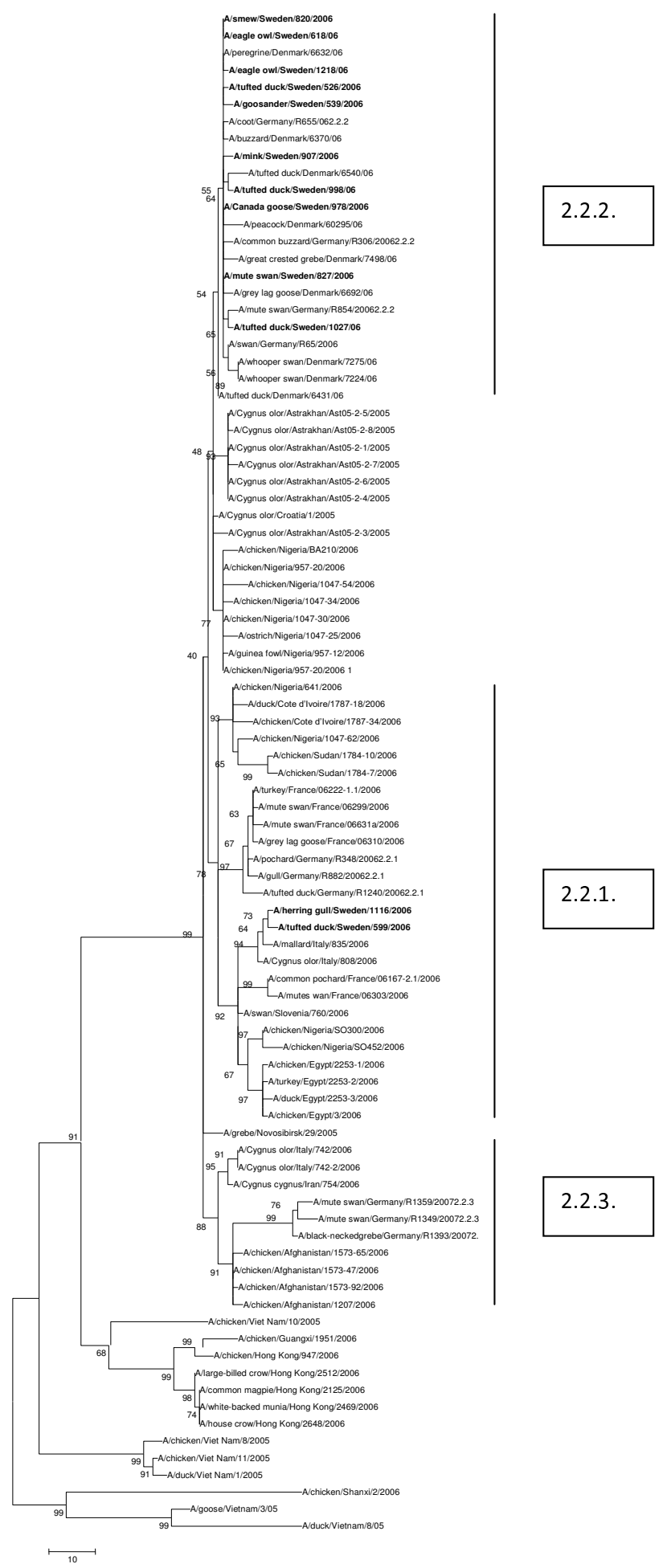

Figure I

Evolutionary relationships of HA genes of Swedish HP H5N I AIVs compared to genetically closely related

H5N I viruses isolated in Europe. The phylogenetic trees were generated by maximum parsimony analysis (neighbor-joining revealed similar tree topologies). Bootstrap values of 1000 resamplings in per cent are indicated at key nodes. The Swedish viruses are highlighted by bold letters. 


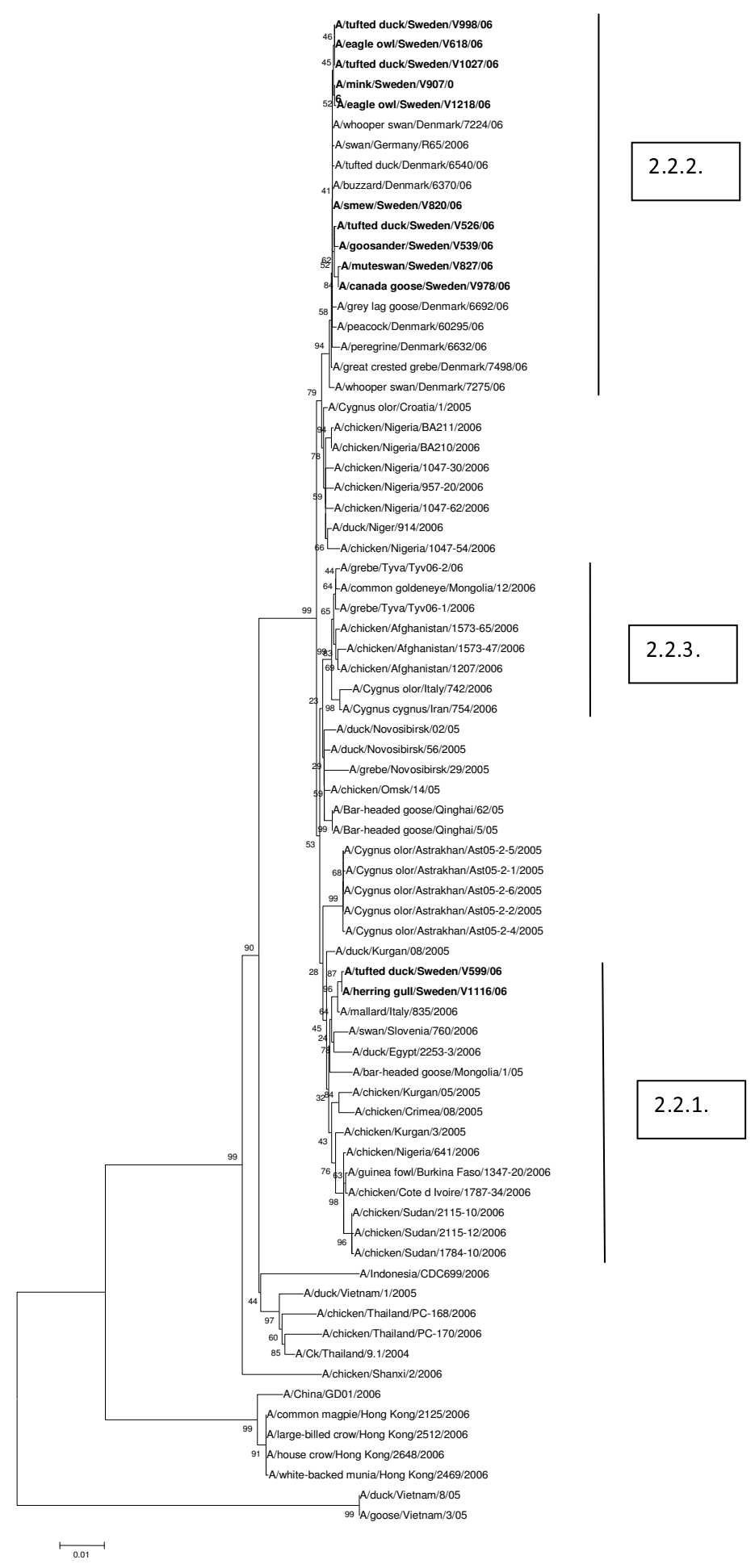

Figure 2

Evolutionary relationships of PB2 genes of Swedish HP H5N I AIVs compared to genetically closely related H5NI viruses isolated in Europe. The phylogenetic trees were generated by maximum parsimony analysis (neighbor-joining revealed similar tree topologies). Bootstrap values of 1000 resamplings in per cent are indicated at key nodes. The Swedish viruses are highlighted by bold letters. 


\section{Molecular characterization}

Characteristic findings regarding the preservation/substitutions at particular amino acid positions along with potential distinctive molecular markers for the Swedish H5N1 viruses are summarized in Additional file 1.

\section{Polymerase genes}

A single amino acid substitution, from glutamic acid (E) to Lysine $(\mathrm{K})$ in position 627 in PB2 is a determinant of mammalian host range $[13,14]$. Most avian isolates have $\mathrm{E}$ in this position. The substitution to $\mathrm{K}$ in this position converts a nonlethal $\mathrm{H} 5 \mathrm{~N} 1$ influenza A virus isolated from a human to a lethal virus in mice [13]. Among the H5N1 HPAIV sequences we investigated a larger proportion of those originating from 1998-2005 had PB2-E627 than more recent isolates. The 2.2.2.-like Swedish viruses along with the most closely related Danish and German isolates encoded $\mathrm{K}$ at this site while the two sub-clade 2.2.1.-like Swedish isolates (A/tufted duck/Sweden/599/ 06 and $\mathrm{A} /$ herring gull/Sweden/1116/06) possessed $\mathrm{E}$ at position 627. The mutations D701N and S714R in PB2 contribute to virulence by enhancing polymerase activity [15]. All Swedish isolates had D and S at position 701 and 714, respectively.

PB1-F2 has been identified as a proapoptotic mitochondrial protein expressed from a second open reading frame of the PB1 gene [16] and it has been shown to contribute to viral pathogenesis in mice [17]. Aspargine in position 66 in PB1-F2 has been demonstrated to play a key role in the pathogenicity of $\mathrm{H} 5 \mathrm{~N} 1$ viruses [18] and its presence was determined in all Swedish viruses. Furthermore, Swedish 2.2.1. subclade viruses had a K26Q substitution compared to 2.2.2. subclade viruses. Isolate $\mathrm{A} /$ tufted duck/Sweden/599/06 solely contained a T323I and a H562P, while A/herring gull/Sweden/1116/06 a V719M substitution, respectively. The $\mathrm{H} 5 \mathrm{~N} 1$ viral polymerase activity is enhanced by the presence of $\mathrm{PB} 2701 \mathrm{~N}$ and $714 \mathrm{R}, \mathrm{PB} 1$ 13P, PA $615 \mathrm{~N}$, further, NP $319 \mathrm{~K}$ and $678 \mathrm{~N}$ [15]. Among the Swedish isolates the presence of PB1 13P was determined.

\section{Surface glycoprotein genes}

The HA sequences of isolates A/Mute swan/Sweden/827/ 06, A/Canada goose/Sweden/978/06, and A/peregrine/ Denmark/6632/06 proved to be identical. The amino acid sequence flanking the cleavage site of the HA gene was PQGERRRKKRGLF alike all other 2.2. viruses with the exception of some French isolates that had the PQGERKRKKR/G sequence [11]. The identified amino acid markers of H5N1 influenza viruses isolated at Qinghai and Poyang Lakes from migratory birds (HA-I99, HA-N268, and NA-R110) were present in all Swedish isolates as well [11]. No "sub-clade"-specific amino acid changes were identified in the HA among the two subgroups of Swedish isolates. All the Swedish isolates had the 238Q and 240G (numbered from the $\mathrm{H} 5$ start codon) which indicates preferred receptor specificity for the avian $\alpha-(2,3)$ linkage to galactose $[19,20]$. All HA sequences contained $6 \mathrm{~N}$-linked potential glycosylation sites, as analysed with NetNglyc server (threshold: 0.5 ) at the following positions: 27, 39, $181,302,500,559$; none of them is adjacent to the cleavage site. Furthermore, the substitutions S145L and A172T, which are associated with viral adaptation to poultry [21] were not determined in association with the Swedish $\mathrm{H} 5 \mathrm{~N} 1$ viruses.

The amino acid substitutions R178I and I248V in HA that were found in the domestic birds of the Danish isolates [22] were not present in any of the Swedish viruses, nor the V73I substitution that was found in the Danish swan isolates. However, the D387N substitution found in the German and most of the Danish isolates was also present in the Swedish isolates.

The H5N1 virus isolated from a mink (A/Sweden/mink/ 2006/V907) was examined in order to reveal any possible adaptation towards mammals. As a result, a unique E513G substitution was found in the HA gene but no substitutions that could be regarded as host-related were found, which is consistent with previous findings, i.e. that a single passage in mammals is not necessarily associated with changes in receptor-binding sites [9].

As in the other 2.2. viruses, NA-R110 was present in the Swedish isolates, and a 20 amino acid deletion was also found at positions 49-68 similarly to the majority of the recent H5N1 strains [22]. The N228S substitution was present only in A/Herring gull/1116/06 Swedish 2.2.1. virus (alike with several other member of the sub-clade) and not in A/Tufted duck/Sweden/599/06 isolate. These two isolates differed further in amino acid residues 414 and 434 by bearing $\mathrm{N} / \mathrm{K}$ and $\mathrm{S} / \mathrm{G}$ corresponding to $\mathrm{A} / \mathrm{Her}-$ ring gull/1116/06 and A/Tufted duck/Sweden/599/06 viruses, respectively. Interestingly, while the Danish and German isolates shared unique amino acids in the NA (G336D), PB1 (K531R) and NS2 (G63E) proteins the Swedish isolates were not homogenous in this regard: although NA-G336D was a characteristic of the Swedish viruses too, two isolates retained the PB1-531K, and NS263G. Reported substitutions in NA, inducing oseltamivir resistance [9], were not found in the Swedish isolates.

\section{The NP and $M$ genes}

The NP-10Y amino acid residue, which may affect the pathogenicity of AIVs [15], was present in all of the Swedish isolates. Concerning the M2 gene, all Swedish viruses contained the L26-V27-A30-S31-G34 amino acid pattern, thus, no adamantan drug resistant variant was revealed [9]. Substitutions S64A and E66A that were present in the 
M2 genes of H5N1 AIV isolates from Hong Kong [11] did not appear in Swedish viruses.

The complete characterization of the NS genes from these isolates was described by Zohari et al., [10], and is not further discussed here.

The effect of substitutions on the predicted antigenicity was investigated among the Swedish isolates for the surface glycoproteins (HA and NA) and for those primarily targeted by the host's cellular immune response (PB2, PA, and NP [23]) (Table 1). The observed amino acid alterations affected the predicted antigenic epitopes in few cases. Regarding the HA in all but one cases 22 epitopes were predicted by the Kolaskar-Tongaonkar approach [24], the exception was strain A/herring gull/Sweden/ $1116 / 06$, bearing a V201M substitution, which resulted in splitting the corresponding GKLCDLDGVKPLILRDCSVAGW predicted epitope (between amino acid residues 55-76) into two smaller ones: GKLCDLD (aa residues 55-61) and PLILRDCSVAGW (aa residues 65-76). The predicted numbers of epitopes in NA were higher for Swedish 2.2.1. viruses than for 2.2.2. viruses (19-20 compared to 17-18). However, in this case no splitting of epitope(s) was predicted due to a change in the amino acid sequence, but rather, the substitutions could be asso- ciated with the appearance of newer epitopes (data not shown). No changes in the number of predicted epitopes was found in for PB2 and PA. In general, the Swedish viruses coded for 15 epitopes on the NP with the only exception of sublineage 2.2.2. virus A/eagle owl/Sweden/ V618/06, which had an additional epitope of seven amino acids between residues 22-28. In summary, the detected amino acid changes among the Swedish viruses appeared to have greater effect on the composition of proteins targeted by the humoral than those targeted by the cellular immune responses, in particular, on the NA gene.

\section{Conclusion}

The incursion of H5N1 HPAIV strains falling into three sub-clades into Europe throughout late 2005 and 2007 has been demonstrated earlier [7]. Further reports and the analysis of the corresponding published sequences revealed the introduction of multiple variants of $\mathrm{H} 5 \mathrm{~N} 1$ HPAIV into several European countries, such as sub-clade 2.2.1. and 2.2.2. viruses into Germany, France, and Sweden $[6,9,11,25]$, and subclade 2.2.1. and 2.2.3. viruses into Italy [7]. The Swedish 2.2.1. sub-clade viruses were closely related to A/Cygnus olor/Italy/808/2006 and A/ mallard/Italy/835/2006 and shared several common nucleotide and amino acid motifs, among them, importantly, the PB2-627E, suggesting that they derived from an

Table I: Differences in number of nucleotide and amino acid compositions, synonymous and nonsynonymous nucleotide substitutions, and predicted antigenic epitopes between sub-clade 2.2.1.-2.2.2. Swedish $\mathrm{H} 5 \mathrm{NI}$ avian influenza viruses.

\begin{tabular}{|c|c|c|c|c|c|c|c|}
\hline \multirow[t]{2}{*}{ Gene } & \multirow{2}{*}{$\begin{array}{c}\text { Region of } \\
\text { comparison/ } \\
\text { nucleotide/ }\end{array}$} & \multicolumn{2}{|c|}{$\begin{array}{l}\text { Difference between sub-clade 2.2.1.-2.2.2. } \\
\text { Swedish viruses }\end{array}$} & \multicolumn{2}{|c|}{$\begin{array}{c}\text { Number of synonymous/ } \\
\text { nonsynonymous nucleotide changes }\end{array}$} & \multicolumn{2}{|c|}{$\begin{array}{l}\text { Average number of predicted } \\
\text { antigenic epitopes }\end{array}$} \\
\hline & & $\begin{array}{l}\text { Average number of } \\
\text { nucleotide } \\
\text { differences }\end{array}$ & $\begin{array}{c}\text { Average number of } \\
\text { amino acid } \\
\text { differences }\end{array}$ & 2.2.1. & 2.2.2. & 2.2.1. & 2.2.2. \\
\hline PB2 & $73-2193$ & 23.7 & 4.5 & $0 / 1$ & $6 / 4$ & 32 & 32 \\
\hline \multirow[t]{2}{*}{ PBI } & $22-2199$ & 20.1 & 6.9 & $6 / 3$ & $10 / 4$ & $\mathrm{Nd}$ & $\mathrm{Nd}$ \\
\hline & & PBI-F2: I.I & I.I & $0 / 0$ & $0 / 1$ & & \\
\hline PA & $60-2091$ & 13 & 3.2 & $1 / 0$ & $3 / 2$ & 28 & 28 \\
\hline $\mathrm{HA}$ & $49-1636$ & 15.5 & 1.5 & $1 / 2$ & $5 / 5$ & 22.5 & 22 \\
\hline NP & I-1497 & 16.1 & 6.2 & $2 / 5$ & $8 / 10$ & 15 & 15.1 \\
\hline NA & $1-1344$ & 14.8 & 8.6 & $10 / 6$ & $9 / 13$ & 19.5 & 17.8 \\
\hline \multirow[t]{2}{*}{$M P$} & MPI: I-950 & 12 & 4.2 & $3 / 2$ & $9 / 14$ & $\mathrm{Nd}$ & $\mathrm{Nd}$ \\
\hline & MP2: I-262 & 5.3 & 2.9 & $0 / 2$ & $4 / 6$ & & \\
\hline \multirow[t]{2}{*}{ NS } & NSI: I-678 & 9.3 & 3.7 & $1 / 1$ & $8 / 14$ & & \\
\hline & NS2: I-366 & 6.8 & 3.5 & $1 / 1$ & $9 / 11$ & $\mathrm{Nd}$ & $\mathrm{Nd}$ \\
\hline
\end{tabular}

Nd: Not done 
earlier progenitor of Southeast Asian origin. The detection of these H5N1 HPAIV strains in Sweden adds further data regarding the spread of 2.2.1. viruses in the North. The accumulation of particular mutations reflects that presumably these viruses have been circulating in the South before the transmission to the northern parts of Europe [9]. Sub-clade 2.2.2. Swedish H5N1 HPAIV isolates proved to be closely related to the contemporary German and Danish isolates, which supports the proposition of the introduction and spread of a single variant of 2.2.2. sub-clade $\mathrm{H} 5 \mathrm{~N} 1$ avian influenza viruses in the Baltic region.

The number and composition of the immune reactive peptides predicted by computing indicated that the surface glycoprotein genes were more affected than the nucleoprotein, polymerase basic protein 2, and polymerase acidic protein, the main targets of the cellular immune responses.

The above observations, alike those with similar objectives, highlight and warrant the importance of whole genome sequencing of HPAIV isolates, in order to improve the surveillance and preparedness against highly pathogenic avian influenza.

\section{Methods}

Viral isolates

The isolates involved in this study are shown in Table 2. They were collected during the HPAI outbreak in Northern Europe in spring 2006 [10].

\section{RT-PCR and nucleotide sequencing}

The collection of specimens, RNA extraction, and RT-PCR amplification of the NS1 sequences was described earlier and the same RNA batches were used for this study that served as targets in the previous investigation [10]. In order to obtain possibly the full length nucleotide sequences of the coding regions of the influenza virus isolates several approaches were combined that comprised of either published protocols/primers $[22,26,27]$ or those developed and used by the Influenza Genome Sequencing Project [[28]; the primer sequences were kindly provided by David Spiro, The J. Craig Venter Institute, Rockville, Maryland, USA), or designed by ourselves. The primer and PCR protocols for sequencing are available from the authors upon request.

\section{Phylogenetic analysis}

For the phylogenetic analyses, a set of H5N1 AIVs that were isolated in Europe, Asia and Africa in 2005 - 2006 was selected and used for all genes. These were collected from the Influenza Virus Resource at NCBI [29] and these were included in the phylogenetic analyses.
Table 2: List of the H5NI HPAIV isolates used in this study

\begin{tabular}{ll}
\hline Isolate name & Species \\
\hline A/tufted duck/Sweden/V526/06 & Aythya fuligula \\
\hline $\mathrm{A} /$ goosander/Sweden/V539/06 & Mergus merganser \\
\hline $\mathrm{A} /$ tufted duck/Sweden/V599/06 & Aythya fuligula \\
\hline $\mathrm{A} /$ eagle owl/Sweden/V6/8/06 & Bubo bubo \\
\hline $\mathrm{A} /$ smew/Sweden/V820/06 & Mergus albellus \\
\hline $\mathrm{A} /$ mute swan/Sweden/V827/06 & Cygnus olor \\
\hline $\mathrm{A} /$ mink/Sweden/V907/06 & Mustela vison \\
\hline $\mathrm{A} /$ canada goose/Sweden/V978/06 & Branta canadensis \\
\hline $\mathrm{A} /$ tufted duck/Sweden/V998/06 & Aythya fuligula \\
\hline $\mathrm{A} /$ tufted duck/Sweden/V1027/06 & Aythya fuligula \\
\hline $\mathrm{A} /$ herring gull/Sweden/VIII6/06 & Larus argentatus \\
\hline $\mathrm{A} /$ eagle owl/Sweden/VI2/8/06 & Bubo bubo \\
\hline
\end{tabular}

For further details of the viruses see reference Zohari et al., 2008 [10].

Sequence assembly, multiple alignment and alignment trimming were performed with the CLC Combined Workbench 3.0.2. bioinformatics software (CLC bio A/S, Aarhus, Denmark). Distance based neighbor joining and character based maximum parsimony phylogenetic trees were generated using the Molecular Evolutionary Genetics Analysis (MEGA) software v.4.0. [30] with 1000 bootstrap replicates. For the neighbor-joining trees, the Kimura-2 substitution model was used. Other models were also tested which showed similar topologies. The evolutionary divergence between the sub-clades was investigated by pairwise analyses over all sequence pairs between the groups by using the MEGA software also. The occurrence and distribution of synonymous and nonsynonymus substitutions was investigated by the DNA Sequence Polymorphism software (Version 4.50.3) software [31]. Computational analysis of the antigenic sites was carried out by using the Kolaskar-Tongaonkar method [24].

\section{Nucleotide sequence accession numbers}

Nucleotide sequences from Swedish H5N1 virus isolates included in this study have been submitted to GenBank with the following accession numbers: PB2: EU889035EU889046, PB1: EU889047-EU889058, PA: EU889059EU889070, HA: EU889071-EU889082, NP: EU889083- 
EU889094, NA: EU889095-EU889106, M: EU889107EU889118.

\section{Competing interests}

The authors declare that they have no competing interests.

\section{Authors' contributions}

IK took part in conception and organized protocol developments, performed sequence analyses, alignments, phylogenies, drafted and wrote the manuscript. PG took part in conception, developed amplification protocols, performed sequence analyses, alignments, phylogenies, contributed to and revised the manuscript. SZ propagated the viruses, provided nucleotide sequences and core data, contributed to the interpretation of the findings and to the writing of the manuscript. KWR took part in conception, performed sequence analyses, alignments, phylogenies, contributed to and revised the manuscript. GM carried out a large portion of PCR and sequencing reactions, sequence data analysis, and contributed to the writing of the manuscript. EW optimized the assays initially and run much of the amplification reactions, helped in literature search and data analysis. MBrytting contributed to conception, took part in and organized data analyses, revised the manuscript. MS and SL participated in sequencing and method optimization, and took part in data analysis and interpretation. AL contributed to conception, organized data analyses, and revised the manuscript. KN took part in the PCR runs and sequencing reactions and contributed to the writing of the manuscript. PT, MBerg, and GC contributed to conception, interpretation of data, and revised the manuscript. BS critically revised the manuscript and gave the final approval for publication.

All authors read and approved the final manuscript.

\section{Additional material}

\section{Additional file 1}

Main amino acid characteristics of the Swedish H5N1 HPAIV isolates. Some major amino acid residues characterizing and discriminating subclade 2.2.1. and 2.2.2. Swedish H5N1 HPAIV isolates are summarized in the table.

Click here for file

[http://www.biomedcentral.com/content/supplementary/1743422X-5-113-S1.doc]

\section{Acknowledgements}

Thanks are due to Elodie Ghedin and David Spiro for their help during the set-up of the amplification protocols and to Béla Lomniczi for his comments on the manuscript. This work was partly supported by the Swedish Emergency Management Agency, the EPIZONE project (Network of Excellence for Epizootic Disease Diagnosis and Control, FP6-2004-Food-3-A), the
Swedish Research Council for Environment, Agricultural Sciences and Spatial Planning (Formas 22I-2006-2169 and Formas 22I-2007-935) projects, and the FLUTEST EU project (Contract No.: 044429). Elisabeth Weiss was supported by the Leonardo da Vinci Mobilität Programme.

\section{References}

I. Xu X, Subbatao K, Cox NJ, Guo Y: Genetic characterization of the pathogenic influenza A/Goose/Guangdong/I/96(H5NI) virus: similarity of its hemagglutinin gene to those of $\mathrm{H} 5 \mathrm{NI}$ viruses from the 1997 outbreaks in Hong Kong. Virology 1999, 261:15-19.

2. Chen H, Smith GJD, Li KS, Wang J, Fan XH, Rayner JM, Vijaykrishna D, Zhang JX, Zhang LJ, Guo CT, Cheung CL, Xu KM, Duan L, Huang K, Qin K, Leung YHC, Wu WL, Lu HR, Chen Y, Xia NS, Naipospos TSP, Yuen KY, Hassan SS, Bahri S, Nguyen TD, Webster RG, Peiris JSM, Guan Y: Establishment of multiple sublineages of H5N I influenza virus in Asia: Implications for pandemic control. Proc Natl Acad Sci USA 2006, 103:2845-2850.

3. Nguyen TD, Nguyen TV, Vijaykrishna D, Webster RG, Guan Y, Peiris JSM, Smith GJD: Multiple sublineages of influenza A virus (H5NI), Vietnam, 2005-2007. Emerg Infect Dis 2008, I4: [http:// www.cdc.gov/EID/content//4/4/632.htm]. [16 April 2008]

4. World Health Organization [http://www.who.int/csr/disease/ avian influenza/Timeline 0806 17.pdf]. Accessed II July 2008

5. Gilbert M, Xiao X, Domenech J, Lubroth J, Martin V, Slingenbergh J: Anatidae migration in the western Palaearctic and spread of highly pathogenic avian influenza $\mathbf{H 5 N I}$ virus. Emerg Infect Dis 2006, I 2:1650-1656.

6. Weber S, Harder T, Starick E, Beer M, Werner O, Hoffmann B, Mettenleiter TC, Mundt E: Molecular analysis of highly athogenic avian influenza virus of subtype $\mathrm{H} 5 \mathrm{NI}$ isolated from wild birds and mammals in northern Germany. J Gen Virol 2007, 88:554-558

7. Salzberg SL, Kingsford C, Cattoli G, Spiro DJ, Janies DA, Aly MM, Brown IH, Couacy-Hymann E, De Mia GM, Dung do H, Guercio A, Joannis T, Maken Ali AS, Osmani A, Padalino I, Saad MD, Saviæ V, Sengamalay NA, Yingst S, Zaborsky J, Zorman-Rojs O, Ghedin E, Capua I: Genome analysis linking recent European and African influenza (H5NI) viruses. Emerg Infect Dis 2007, I3:7I3-7I8.

8. Writing Committee of the Second World Health Organization Consultation on Clinical Aspects of Human Infection with Avian Influenza A (H5NI) Virus: Update on Avian Influenza A (H5NI) Virus Infection in Humans. N Engl J Med 2008, 358:26I-273.

9. Starick E, Beer M, Hoffmann B, Staubach C, Werner O, Globig A, Strebelow G, Grund C, Durban M, Conraths FJ, Mettenleiter T, Harder T: Phylogenetic analyses of highly pathogenic avian influenza virus isolates from Germany in 2006 and 2007 suggest at least three separate introductions of $\mathrm{H5N}$ I virus. Vet Microbiol 2008, I 28:243-252.

10. Zohari S, Gyarmati P, Thorén P, Czifra Gy, Bröjer C, Belák S, Berg M: Genetic characterization of the NS gene indicates co-circulation of two sub-lineages of highly pathogenic avian influenza virus of H5NI subtype in Northern Europe in 2006. Virus Genes 2008, 36: 1 17-25.

II. Le Gall-Reculé G, Briand FX, Schmitz A, Guionie O, Massin P, Jestin $\checkmark$ : Double introduction of highly pathogenic $\mathrm{H} 5 \mathrm{NI}$ avian influenza virus into France in early 2006. Avian Pathology 2008, 37:15-23.

12. Lu G, Rowley T, Garten R, Donis RO: FluGenome: a web tool for genotyping influenza A virus. Nucleic Acids Res 2007:W275-279.

13. Shinya K, Hamm S, Hatta M, Ito $H$, Ito $T$, Kawaoka $Y$ : PB2 amino acid at position 627 affects replicative efficiency, but not cell tropism, of Hong Kong H5NI influenza A viruses in mice. Virology 2004, 320:258-266.

14. Subbarao EK, London W, Murphy BR: A single amino acid in the PB2 gene of influenza A virus is a determinant of host range. Jirol 1993, 67:1761-1764.

15. Gabriel G, Dauber B, Wolff T, Planz O, Klenk H-D, Stech J: The viral polymerase mediates adaptation of an avian influenza virus to a mammalian host. Proc Natl Acad Sci USA 2005, 102:18590-18595.

16. Chen W, Calvo PA, Malide D, Gibbs J, Schubert U, Bacik I, Basta S, O'Neill R, Schickli J, Palese P, Henklein P, Bennink JR, Yewdell JW: A novel influenza $A$ virus mitochondrial protein that induces cell death. Nat Med 200I, 7:1306-1312. 
17. Zamarin D, Ortigoza MB, Palese P: Influenza A virus PBI-PF2 protein contributes to viral pathogenesis in mice. J Virol 2006, 80:7976-7983.

18. Conenello GM, Zamarin D, Perrone LA, Tumpey T, Palese P: A Single Mutation in the PBI-F2 of H5NI (HK/97) and 1918 Influenza A Viruses Contributes to Increased Virulence. PLoS Pathog 2007, 3(10): el4I.

19. Matrosovich MN, Matrosovich TY, Gray T, Roberts NA, Klenk HD: Human and avian influenza viruses target different cell types in cultures of human airway epithelium. Proc Natl Acad Sci USA 2004, I 0 I:4620-4624.

20. Suzuki Y, Ito T, Suzuki T, Holland RE Jr, Chambers TM, Kiso M, Ishida $H$, Kawaoka $Y$ : Sialic acid species as a determinant of the host range of influenza A viruses. J Virol 2000, 74: I |825-I I83।.

21. Perdue ML, Suarez DL: Structural features of the avian influenza virus hemagglutinin that influence virulence. Veterinary Microbiology 2000, 74:77-86.

22. Bragstad K, Jorgensen PH, Handberg K, Hammer AS, Kabell S, Fomsgaard A: First introduction of highly pathogenic H5N I avian influenza viruses in wild and domestic birds in Denmark, Northern Europe. Vir J 2007, 4:43.

23. Subbarao K, Joseph T: Scientific barriers to developing vaccines against avian influenza viruses. Nature Reviews - Immunology 2007, 7:267-278.

24. Kolaskar AS, Tongaonkar PC: A semi-empirical method for prediction of antigenic determinants on protein antigens. FEBS Lett 1990, 276: 172-4.

25. Rinder M, Lang V, Fuchs C, Marx-Hafner A, Bogner KH, Neubauer A, Büttner M, Rinder H: Genetic evidence for multi-event imports of avian influenza virus A (H5NI) into Bavaria, Germany. J Vet Diagn Invest 2007, 19:279-282.

26. Hoffmann E, Stech J, Guan Y, Webster RG, Perez DR: Universal primer set for the full-length amplification of all influenza $A$ viruses. Arch Virol 200I, 146:2275-2289.

27. Li OT, Barr I, Leung CY, Chen H, Guan Y, Peiris JS, Poon LL: Reliable universal RT-PCR assays for studying influenza polymerase subunit gene sequences from all 16 haemagglutinin subtypes. J Virol Methods 2007, 142:218-22.

28. Ghedin E, Sengamalay NA, Shumway M, Zaborsky J, Feldblyum T, Subbu V, Spiro DJ, Sitz J, Koo H, Bolotov P, Dernovoy D, Tatusova T, Bao Y, St George K, Taylor J, Lipman DJ, Fraser CM, Taubenberger $\mathrm{JK}$, Salzberg SL: Large-scale sequencing of human influenza reveals the dynamic nature of viral genome evolution. Nature 2005, 437:1162-1166.

29. Influenza Virus Resource 2004 [http://www.ncbi.nlm.nih.gov/ genomes/FLU/FLU.html].

30. Tamura K, Dudley J, Nei M, Kumar S: Molecular Evolutionary Genetics Analysis (MEGA) software version 4.0. Mol Biol Evol 2007, 24:1596-1599.

31. Rozas J, Sanchez-DelBarrio JC, Messeguer X, Rozas R: DnaSP, DNA polymorphism analyses by the coalescent and other methods. Bioinformatics 2003, 19:2496-2497.

Publish with Bio Med Central and every scientist can read your work free of charge

"BioMed Central will be the most significant development for disseminating the results of biomedical research in our lifetime. "

Sir Paul Nurse, Cancer Research UK

Your research papers will be:

- available free of charge to the entire biomedical community

- peer reviewed and published immediately upon acceptance

- cited in PubMed and archived on PubMed Central

- yours - you keep the copyright
BioMedcentral 